Article

\title{
The Use of Video to Evaluate On-Farm Demonstrations as a Tactile Space for Learning
}

\author{
Hanne Cooreman ${ }^{1, * \mathbb{C}}$, Joke Vandenabeele ${ }^{2}$, Lies Debruyne ${ }^{3}$ and Fleur Marchand ${ }^{3,4}$ (D) \\ 1 KU Leuven \& Social Sciences Unit Flanders Research Institute for Agriculture, Fisheries and Food (ILVO), \\ 9820 Merelbeke, Belgium \\ 2 KU Leuven-Education, Culture and Society-Laboratory for Education and Society (ECS-LES), 3000 Leuven, \\ Belgium; joke.vandenabeele@kuleuven.be \\ 3 Social Sciences Unit, Flanders Research Institute for Agriculture, Fisheries and Food (ILVO), 9820 Merelbeke, \\ Belgium; lies.debruyne@ilvo.vlaanderen.be (L.D.); fleur.marchand@ilvo.vlaanderen.be (F.M.) \\ 4 Institute of Environment and Sustainable Development, University of Antwerp, 2020 Antwerp, Belgium \\ * Correspondence: hanne.cooreman@ilvo.vlaanderen.be
}

Received: 30 April 2020; Accepted: 22 May 2020; Published: 26 May 2020

\begin{abstract}
Tactile spaces as learning environments influence individuals' attitudes through social embeddedness or interconnections among people, and physical embodiedness through experiencing surroundings, potentially fostering deep commitments. When on-farm demonstrations operate as tactile spaces, they could potentially support the adoption of innovative agricultural practices. In this article, we introduce video analysis as a methodological approach to evaluate this potential of on-farm demonstration (OFD) as tactile spaces. We reflect upon this methodology with a lens on three Belgian on-farm demonstrations, each on a different topic with a different participant group, all including farmers. As a first result, this method assists in defining strengths and weaknesses of an OFD in terms of using its potential as a rich learning environment. Based on our cases, we suggest deliberately incorporating physical interaction opportunities and verbal references to the surroundings during OFDs, as our data reveals that physical embodiedness opportunities stimulate verbal and physical interactions. However, more research should confirm this. Secondly, our research resulted in lessons learned for future use of video to evaluate OFDs as tactile spaces, building on the VDA methodological framework of Nassauer and Legewie (2018). We summarise our insights in methodological guidelines, which can serve as a starting point to guide future research.
\end{abstract}

Keywords: tactile space; on-farm demonstration; peer learning; video; VDA; more-thanrepresentational knowledge; physical embodiedness; social embeddedness

\section{Introduction}

Our fast changing context, characterised by climate change, the need to address complex, often local, problems related to sustainable resource management, and the globalised markets based on technology and knowledge, has initiated a more complex system of knowledge exchange compared with the past [1]. Therefore, to address these complex challenges related to the aspiration of a more sustainable future, innovation should be more "co-produced" through interactions between all stakeholders [2]. Participatory, more bottom-up approaches in agricultural extension represent this recent trend, associated with a number of benefits, including higher rates of adoption and practice change, positive effects on yield, income and productivity; greater well-being, increased knowledge and skills associated with empowerment; and the availability of peer support [1,3-5]. 
We argue that on-farm demonstrations (OFDs) as an agricultural knowledge exchange activity fit well in this shift in approach towards more participatory agricultural education activities [6]. We define an OFD as: the diverse means for providing farmers with "an explanation, display, illustration, or experiment showing how something works" (Collins English Dictionary) that can be subsequently applied in their own farming practices to bring about positive changes on their farm [4,7]. OFDs take place preferably on actual working farms so the demonstration can be visualised in real life conditions. OFDs can thus provide the opportunity for farmers to physically gather, discuss together with both peers and experts, jointly solve problems, monitor experiments, observe and compare practices in similar contexts to their own, as well as experience hands-on activities [4]. Therefore, it is not surprising that OFDs have become an established practice in a number of advisory and extension systems [8]. It is a versatile practice that can be used for a great variety of advisory and extension strategies (e.g., supporting horizontal knowledge exchange; generation of policy and/or technological innovations; and supporting organisation development) and functions (raising awareness and consciousness; exploration of views and issues; communication on innovations) [6]. Another reason for our focus on OFDs are the multiple studies confirming demonstrations as a preferred way to learn by farmers. Franz et al. [9], for example, summarised the most preferred learning methods by farmers, of which the first five were: hands-on, demonstration, farm visit, field day and discussion. We believe that OFDs as learning spaces have the potential to combine multiple of these preferred methods, for example by including hands-on activities and discussion sessions during an OFD.

In this study, we aim to go beyond studying interactions between people by also articulating influences of the environmental surroundings an OFD can offer. We introduce the concept of 'tactile space' in our research on OFD and found evidence for this in a statement made by Cowan et al. [10]: "Tactile spaces can serve as participatory, experiential, and compelling counterpoints to traditional 'top-down' approaches to diffusing information about innovative agricultural and practices." A "tactile space", according to Carolan [11], refers to more than a space for seeing and/or touching. It influences individuals" attitudes about new technologies, practices, and ideas through both "embeddedness and embodiedness", by fostering "deep commitments". A change in "deep commitments" is explained by Carolan as a change in behaviours that are informed by a sense of care for others and the environment [11]. More specifically, "deep commitments" are "deep" because they persist whether or not the market incentivises them to do so. The encouragement to change behaviour thus derives from someone's drive to care for the environment. More specifically, tactile space involves interconnections among people (i.e., social embeddedness) and physical negotiations with environmental surroundings (i.e., physical embodiedness). This implies that individuals can see, taste, touch, smell and hear for themselves the phenomena around which knowledge claims and constructs are made [11]. This goes beyond learning of representational knowledge and draws attention to learning of more-than-representational knowledge. This focus on tactile spaces grew out of similar criticisms on a too narrow focus on "representational knowledge", grounded in cultural geography [12] and introduced to the field of agriculture by Carolan [13]. Social theorists point out the relevance of embodied and sensory knowledge and therefore put the concept of non-representational knowledge forward. Carolan prefers the term "more-than-representational" because he does not believe in representing fundamentally non-representable knowledge. He explains his understanding of using the more preferred concept 'more-than-representational knowledge' in research as follows:

It is not that we cannot represent sensuous, corporeal, lived experience but that the moment we do so we immediately lose something. Representations tell only part of the story, yet they still have a story to tell, however incomplete. So I admit: we cannot literally feel in these pages what respondents truly experienced in their lived experience. But this does not mean that we cannot at least get a taste of their world through their words. (Carolan [13] referencing to participant interviews) 
More-than-representational knowledge is thus fostered through embodied learning, wherein the knowledge obtained is not represented easily through language only. Imagine a farmer trying to explain to someone inexperienced how to use a tractor. This learning process would be better facilitated if the learner could immediately try it out sitting in the tractor, instead of trying to grasp words only. More-than-representational knowledge is found in the here-and-now and in ways in which rural experiences are felt and sensed through bodily actions [13]. It involves assimilating stimuli using multiple senses [10,13]. As Carolan [11] explains, when the physical space (e.g., the field) becomes the physical representation of conveyed knowledge, and more-than-representational knowledge is also mediated through that space, the space is considered a tactile space. Carolan [14] illustrates this by describing field days organised by a sustainable agriculture organisation in Iowa: "those in attendance did not merely stand idly by and absorb information. Rather, they listened, touched, walked through, and discussed the knowledge claims ... Growers could engage with the knowledge claims directly, via active engagement in sensory rich tactile space, and decide for themselves which farming techniques and practices to adopt or not". Carolan [13] stated that "those involved in these spaces are encouraged to see problems as more than mere 'puzzles' which cannot be resolved through quick technological fixes. This nurtures a systemic view, where connections are highlighted between people, social structures, and the environment." Therefore, learning during an OFD as a tactile space could be a stimulating and effective way to learn about more sustainable agriculture because sustainability issues are known to entail potentially conflicting values, beliefs and points of view on the 'most desirable' solutions [15]. Above arguments feed our hypothesis that evaluating OFDs through the lens of tactile spaces has the potential to improve future OFDs and positively influence a farmer's learning of a demonstrated innovation.

As a measure of learning effectiveness of an OFD, we want to evaluate attendees' learning opportunities regarding the demonstrated agricultural practices. One well-known option could be to use post OFD surveys (see materials, [16]). These surveys can give us an idea of how effective the farmers rated the demo to have been, and how they experienced the demo by indicating if they agreed or not with specific statements. Although this provides us with valuable information on what participants thought of the demo, this does not give us any idea of how exactly they interacted with the OFD as a tactile space.

In the search of a method for grasping more-than-representational knowledge mediation and sharing, a broad range of educational research has already shown that to fully understand how people learn, it is important to look beyond the individual, pointing also to the importance of understanding interactions between individuals and artefacts [17]. The use of video as a data collection tool seems valuable in this respect for several reasons. Firstly, it is a comprehensive data source, capturing audio, such as talk, but also gaze, gesture, movement and interactions in a format that is available for repeated viewing. These features make video an important source for capturing and analysing social embeddedness and physical embodiedness, crucial to a tactile space. Secondly, data transparency and reproducibility of findings are more limited when using only participant observations [18]. Thirdly, participant observations and other data types, such as survey data or interviews, are inherently unable to ensure optimal capture of an event under study because participants are unable to take in and recall all relevant information from a situation [19]. However, evidence on how people interpreted a situation is captured more easily with a type of interview, which is an argument for using triangulation with other data types in addition to video data.

In the search for a sound analytical framework for video data analysis, we came across the recent proposal of Nassauer and Legewie [18] (Table 1). They label their analytic strategy video data analysis (VDA). They developed a methodological framework around VDA, which aims for interdisciplinary use, with explicit analytic tools, procedures, and quality criteria, as this has not been developed before. According to the authors, VDA builds on different traditions in visual studies: "It is similar to ethnography in its focus on situational dynamics. Like experimental behavioral studies in psychology, it relies on detailed analysis of recorded individual and social behaviors. It resembles multimodal 
interaction analysis in its goal of analyzing situations on all relevant interactional dimensions" such as communication channels. These authors show that visual data studies from non-laboratory settings are being increasingly employed since the 2000s, as a basis for researching social phenomena, explaining a process or outcome through focusing on aspects such as peoples' interactions and movements, or even facial expressions and body postures [18]. It has been applied in different fields such as sociology, social psychology and education [20]; for example, in conversation analytical (CA) studies on learning [21]. A conversation analytical study could already unravel a part of our research interest, more specifically on the dynamics of the verbal interactions happening during an OFD, but this type of study would not be enough to also capture the dynamics of non-verbal interaction with the surroundings. Another strong argument of building on VDA for our research focus is their argument that the context of a situation can be coded regarding physical and social dimensions, and both should be incorporated during VDA. This is exactly what we want to capture when studying and evaluating an OFD as a tactile space. Therefore, we applied their methodological framework, as presented in Table 1 in our own research, for refining our video protocol, analysing our data and summarising our methodological suggestions for evaluating OFDs as tactile spaces.

Table 1. Methodological framework for VDA as proposed by Nassauer and Legewie [18].

\begin{tabular}{|c|c|}
\hline \multicolumn{2}{|l|}{ Research Agenda } \\
\hline Analyses situational dynamics & $\begin{array}{l}\text { - } \quad \text { Focus on natural behaviour. } \\
\text { - } \quad \text { Behaviour, emotions, and interactions. } \\
\text { that help explaining outcomes. }\end{array}$ \\
\hline \multicolumn{2}{|l|}{ Unit of Analysis } \\
\hline Focus on the depicted & $\begin{array}{l}\text { - Raw content of visual data: objects, persons, surroundings, } \\
\text { and the way they interact. }\end{array}$ \\
\hline \multicolumn{2}{|l|}{ Analytic Potential } \\
\hline & $\begin{array}{l}\text { - } \quad \text { Possibility to analyse situations frame by frame. } \\
\text { - Increasing reliability by involving several researchers in } \\
\text { analysis of the exact same primary data. } \\
\text { - Studying rare events through video footage and photographs. }\end{array}$ \\
\hline \multicolumn{2}{|l|}{ Analytic Tool Kit } \\
\hline Analytic dimensions & $\begin{array}{l}\text { - Face and body: movement of mouth and jaw, eye region, } \\
\text { forehead; body postures, head, hands and neck. } \\
\text { Interactions: movement in space, using items, engaging } \\
\text { others physically, gestures and verbal communication. } \\
\text { - Context: physical and social. }\end{array}$ \\
\hline Analytic procedures & $\begin{array}{ll}\text { - } & \text { Coding situations. } \\
\text { - } & \text { Reconstructing processes and events. } \\
\text { - } & \text { Identifying causal links. }\end{array}$ \\
\hline \multicolumn{2}{|l|}{ Criteria for Validity } \\
\hline Optimal capture & $\begin{array}{l}\text { - } \quad \text { Optimal capture of duration, space, and participants. } \\
\text { - } \quad \text { Ensuring sufficient quality of recording. } \\
\text { - } \quad \text { Triangulation as a possible strategy. }\end{array}$ \\
\hline Natural behaviour & $\begin{array}{l}\text { - Reactivity as main challenge: possibility that actors adapt } \\
\text { their behaviour due to the presence of a recording device. } \\
\text { Three key questions to assess reactivity: Were participants } \\
\text { aware? Did they possibly adapt behaviour? Could } \\
\text { adaptation introduce bias into data? }\end{array}$ \\
\hline
\end{tabular}


In the materials and methods section we describe in depth the development process of our video methodology. In the results and discussion section, we reflect on two questions: what do we learn from video analysis related to the organisation of OFDs as a tactile space, and how should we put this methodologically in practice, building on the framework of VDA [18], to evaluate OFDs through the lens of tactile space.

\section{Materials and Methods}

\subsection{Audiovisual Material for Grasping the Tactile Space: Filming Guideline}

To enable the use of video material as a first data source and avoid data overload by not having a clear focus before filming [22], we developed in a first step a filming guideline, focusing on the two main dynamics of tactile space and peer learning. In terms of units of analysis, we aimed to grasp physical embodiedness by focusing on engagements with the environment using different senses (smell, touch, hearing, taste and sight) and social embeddedness by focussing on different forms of communication, including: a demonstrator who is sharing knowledge, a participant who is sharing knowledge, a demonstrator asking questions to participants, participants asking questions to the demonstrator and discussions. Beforehand, we aimed to capture at least $5 \mathrm{~min}$ of each of these units of analysis we could observe. We mostly aimed the camera at the main speaker during formal moments, such as a participant asking a question to the demonstrator while everyone can hear the question as well as the answer, or the demonstrator trying to explain something to the whole group of participants, aiming to get as many participants in the frame at the same time. Exceptions to this arose when specific sensory experiences could be carried out, such as touching the soil, tasting or smelling something. On these occasions, we aimed to capture the exact experience. We knew that with only one camera, we could not focus on informal moments of conversations between smaller groups of participants. By "informal moments" we mean unguided conversations happening between participants. We decided to focus only on informal moments when there was no formal guidance of an advisor, host farmer or demonstrator, also referred to as the main speaker, going on at the same time.

To be as unobtrusive as possible during the OFDs, the researcher held an action camera with an additional audio recorder on the chest. In line with Nassauer and Legewie [18], this way of filming should ensure participants would not change their authentic behaviour too much and quickly forget the presence of a camera filming the scene. Analysing a video in which people adapted their behaviours poses a problem for validity during VDA [18]. To meet ethical requirements, we announced that we would record the OFD on video and asked for the permission of the organisers and participants, explaining that the images would not be published. One other accompanying researcher took field notes wearing an additional audio recorder, mainly as back up for the first recorder. As is also recommended by VDA, we tried to capture all relevant actors from start to finish of the OFD, trying our best to ensure that no part of an interaction is missing and that nothing is left out due to the angle of filming. Specific possible issues to avoid could include people blocking the view of events or interactions, and aspects being too far from the camera to be discernible [18].

\subsection{Participants and Cases}

We gathered data during three Belgian OFDs as part of the AgriDemo-F2F project (January 2017-June 2019). For each case, we have approximately one hour of video material.

Case 1. This OFD happened outside on a one-man farm combining livestock, arable land for different cereal species, (nut) trees and rotation of meadows. The demonstrator was the farmer. The attendees are one group of about 40 international agroforestry conference attendees who chose this farm as part of a field trip. There was one conference organiser leading the group.

Case 2. This OFD took place on a family farm, which recently turned to organic production of mostly maize. The farmer gave a short introduction, then an advisor of a big farmers' organisation took over and guided the demonstration of eight different machines for mechanical weeding in maize 
one by one working in the field. He let the demonstrators of each machine speak, after introducing them and their machines. About 100 attendees showed up, consisting of a mix of both organic and conventional farmers, researchers and retail representatives.

Case 3. Dairy family farm with milking robots and (new) stables, equipped with the latest innovative elements because they believe in their benefit to the wellbeing of the cows and to make their own life easier. A guided farm visit by the farmer's wife followed up presentations, held in their brand new meeting room, on a new decision support tool to optimise dairy cattle management, presented by a few researchers and advisers. About 40 attendees, mostly dairy farmers, showed up.

These three OFDs can be understood as potential tactile spaces. We argue that some elements of tactile space are evident for these three cases, while others are more difficult to observe during these types of OFDs. The surroundings of an actual working farm on which innovations are demonstrated ensure dynamic coexistence with the present, allowing attendees to be shaped by these spaces but also the spaces to be influenced by the attendees [11]. The dialogues that take place between the attendees, including the host farmer, can lead to knowledge and insights that could lead to changes on the farm. These are important characteristics of a tactile space, together with the previously mentioned opportunities for physical embodiedness and social embeddedness. In addition, attendees in all three cases deliberately chose to take part in the OFD, either as farmer or as another type of expert. Therefore, already a certain level of commitment towards one of these three farming systems could be assumed. Through engaging with the surroundings of the OFD, the organisers, host-farmers and other attendees before, during and after the event, it is possible that already existing commitments are strengthened, weakened [23], or that new commitments are formed. The topics of the first two OFDs, agroforestry and mechanical weeding for organic farming, are not the most market-driven farming practices. The third OFD focused more on the economical aspect, but also showed innovations in the stables aiming at the wellbeing of the cows. These OFDs were a one-time event, and thus short-lived, which is not ideal for forming relational engagements between the attendee and the knowledge conveyed through the tactile space. However, these could already lead to interesting outcomes and further develop our understanding of OFDs as tactile space [10]. To evaluate change in deep commitments of host-farmers, demonstrators, as well as attendees, triangulation with for example interviews would be necessary, an argument we refer back to in the discussion.

\subsection{Data Analysis}

We analysed the data of the video using Nvivo Pro 11. As we expected, we had to engage in multiple iterative cycles of analysis of the audiovisual materials [24]. In the first round, we focused on the verbal interactions during each OFD. For example, we coded the times of each moment when a question was asked and by whom (demonstrator, participant, etc.), wrote them out and counted them. We coded the starting and stopping time of each moment when someone else started explaining something. We coded them as a discussion when on a same topic, more than two people shared knowledge or asked a question. During the second round of watching the audiovisual material, we focused on physical interactions with the surroundings. We noted the starting and stopping time when the group moved to another place, when the main speaker pointed out something physically, or when specific sensory experiences were visibly carried out (for example, a demonstrator inviting participants to hear, smell, taste or touch something, or look in a specific direction). Of course, with our approach, we could not grasp what every attendee was experiencing with all their senses during the OFD. We described the movement and the notable sensory experiences. For example:

The machine starts driving and working the soil. Most attendees walk right behind the working machine and look very closely at the soil. Some attendees touch the soil. (Case 2, 32'29"-33'39") 
In the third round, we focused on informal interactions, as we noticed during the first two rounds that many participants talk to each other informally, even during moments when the main speaker is talking. However, we found out that we did not have enough qualitative audiovisual material capturing this to investigate these interactions. The audio was not clear enough to determine both the verbal information given by the main speaker and coincidental informal conversations happening close to the camera. In the fourth round, concerning both physical embodiedness and social embeddedness, we coded the moments of the OFD during which the main speaker makes clear verbal references to the surroundings, as we noticed during the previous rounds that this might influence the behaviour of the attendees.

\section{I planted some oak and ash here (pointing at location close by) (Case 1, +- 21'55")}

In the following step, as proposed by VDA [18], we mapped out categorised units for both physical embodiedness (for example, moments of touching or walking around) and social embeddedness (for example, moments when a participant asked a question) over the duration of the OFD, in search for notable patterns. We investigated the timing, frequency and duration of the interactions, in line with VDA recommendations.

\section{Results}

\subsection{OFDs as a Tactile Space}

\subsubsection{Social Embeddedness and Peer Learning}

Our video data analysis allowed us to map social interaction to a certain depth. Taking a closer look at the guided verbal interactions during formal moments of Case 2, we notice only three short moments of questions asked by participants and answered by the demonstrator. These three moments represent only a small part of the total OFD time, which was mainly filled with a one-way explanation by the demonstrator. Towards the end of the OFD, no more formal moments of guided verbal interaction are observed, which could indicate that participants are, for example, communicating among themselves informally or interacting with the environment instead of verbally interacting with the demonstrator. This is a huge contrast with the approach in Case 1 and visualised in Figure 1 (Case 1) and Figure 2 (Case 2). During Case 1, clearly more questioning during formal moments took place, even when initiated by the demonstrator towards the participants. The demonstrator engaged participants, for example, by asking them: "Do you know which is the richest country in the world?" or "Do you eat quinoa?" Something similar did not happen in the second or third case. The first and third case (Figure 3) also had clearly more questions asked by participants during formal moments. Questions during the first case included, for example: "How many cows do you have?"; "Is this your experimental area?"; "How did you choose the variety of chestnut?"; and "How old are the trees?" Apart from these questions, about one fourth of the total OFD time in the first case was taken up by discussions in which multiple participants took part. Topics included "wasp plague management" and "money from the EU or local government as incentive to plant trees". During the second and the third case, we did not observe as many discussions or sharing of own knowledge by farmers during formal moments.

In the second case, more questions and discussions could have happened during informal talks in smaller groups, which frequently and easily arose during the one-way explanations by the adviser as the main speaker. This did not happen to the same extent in third case, and even less in the first case. Apart from the louder volume of the verbal explanation of the adviser in Case 2, the group size of 100 participants in the second case, compared to 40 in the first and the third, probably also enabled more easily the unstructured forming of smaller groups informally talking to each other. Of course, talking to colleagues during informal moments could also stimulate peer learning. However, in the second case and in mainly the second part of the third case, which took place during a guided farm walk, this meant a trade-off for participants between listening to the main speaker and talking to each other. As a participant, you could decide to stay behind and talk to a colleague, or you could move 
closer to main speaker and listen to their explanation. However, standing further away from the main speaker could mean that you could not hear the explanation because of other participants next to you who were talking to each other.

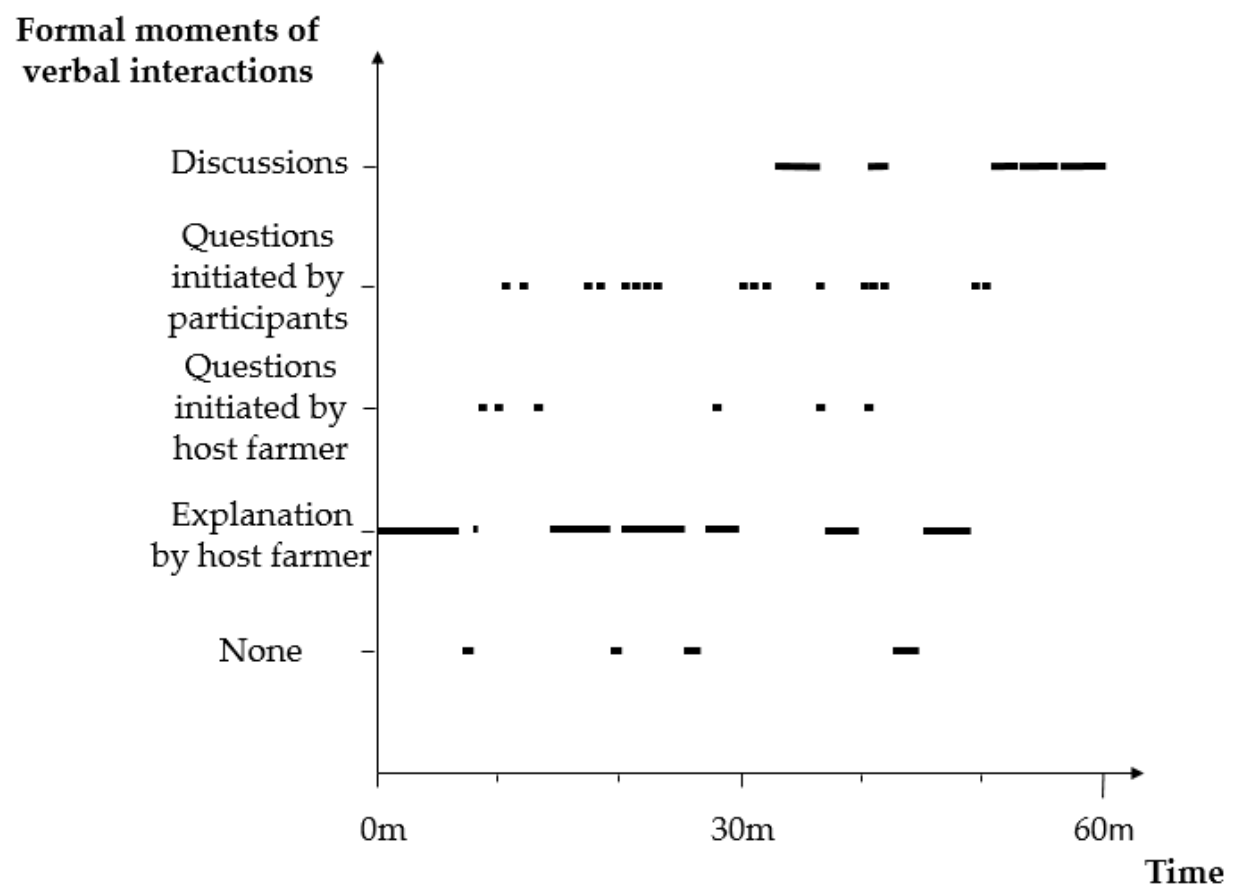

Figure 1. Categorised formal moments of verbal interactions over time, Case 1.

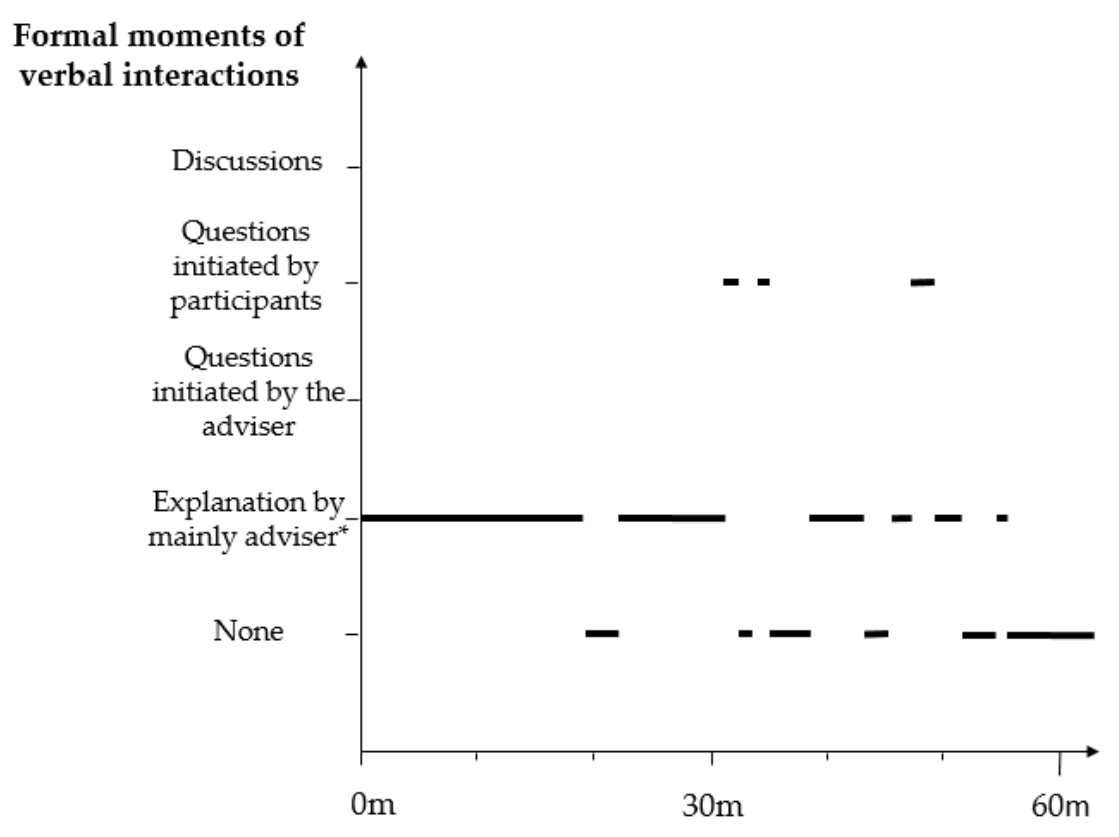

Time

Figure 2. Categorised formal moments of verbal interactions over time, Case 2. ${ }^{*}$ During the first block of explanation, the host-farmer himself elaborates on the history of the farm for $3 \mathrm{~min}$. 


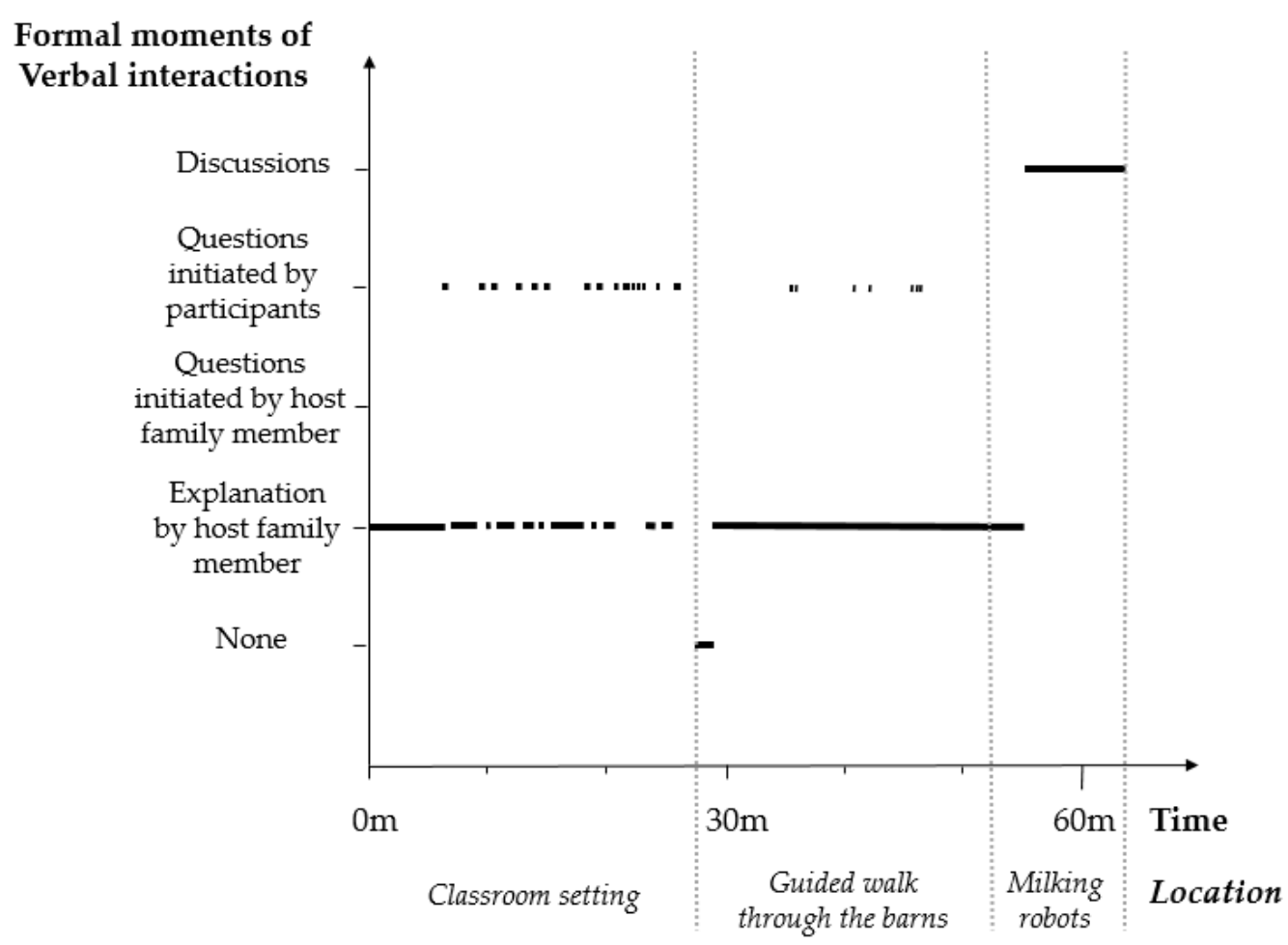

Figure 3. Categorised formal moments of verbal interactions over time, Case 3.

In Case 3, we also noticed an influence of the space on the formal moments of verbal interaction (Figure 3). Since Case 1 and 2 happened outside in the field for the complete duration of the OFD, we couldn't notice this dynamic for these cases. The first half of Case 3 took place in a classroom setting, during which most participants seemed to quietly listen to the explanation of one of the family members, father, mother and son, who complemented each other's answers to questions a couple of times. Multiple questions were asked, of which most were asked by one of the external organisers, but a few were also asked by the attending farmers. The next part of the OFD could be described as more "chaotic" and consisted of a guided walk through mainly the barns. During this walk, the farmer's wife did most of the explanation, but she kept talking even when participants were walking, and only to those who were standing close to her. The participants in the back could not understand what she was talking about, as she simply did not speak loud enough. This is not represented in Figure 4, but the informal conversations between participants standing further away from the farmer's wife increased notably compared to the first half of the OFD in the classroom. The last ten minutes of the OFD took place in a small noisy room next to the milking robots. At one side of the room, the farmer was explaining and discussing the milking robots with the nearby-standing participants. The farmer's wife was doing the same at the other side of the room. There were too many participants to fit comfortably in the room and to provide everyone with a spot close enough to one of the demonstrators to follow the conversation. Again, only the ones standing next to the farmer or his wife, or the ones who deliberately took the initiative to move close enough, could follow and participate in the conversation. Other participants started conversations with each other in small groups. Case 3 thus illustrates how a change of location can easily and perhaps unwantedly influence verbal interactions during an OFD. 


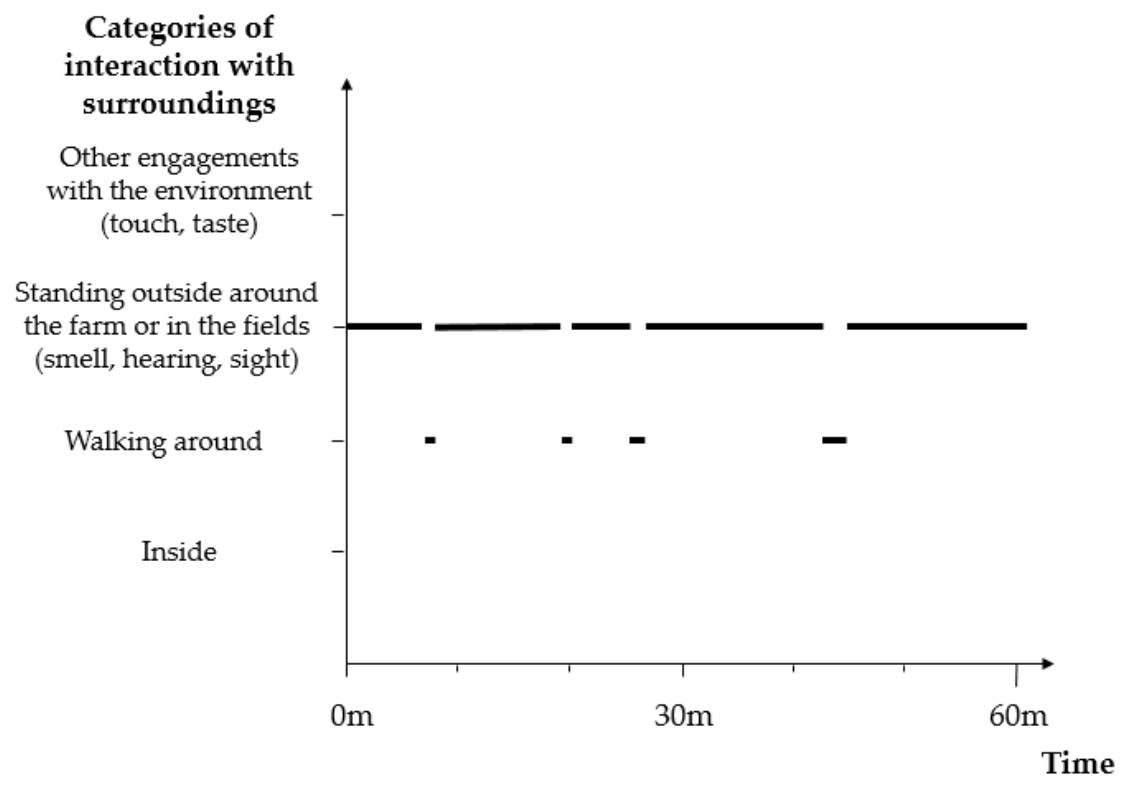

Figure 4. Interaction with surroundings over time, Case 1.

\subsubsection{The Surroundings and Physical Embodiedness}

During Case 1, apart from standing and walking through the fields and looking around or in the direction of what the demonstrator is explaining, no notable sensory experiences were observed (Figure 4). This is in contrast with Case 2, for which we witnessed physical embodiedness in terms of farmers taking the opportunity to immediately examine the soil worked by the machines through touching, feeling and even smelling the soil (Figure 5). Not all participants engaged in these activities, or at the same time. Some were examining the soil or touching the machines even when the demonstrator was explaining. We noticed that sensory experiences, such as examining the soil with the hands, seemed to fuel informal conversations between farmers, debating on the characteristics of the soil they were physically examining.

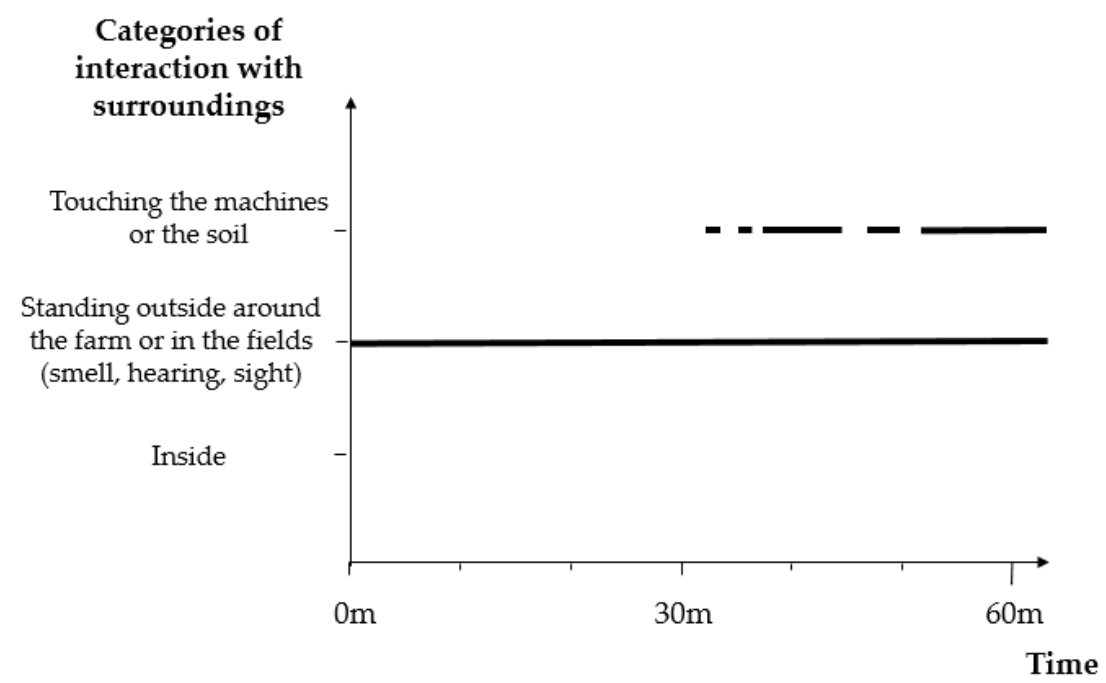

Figure 5. Interaction with surroundings over time, Case 2.

During Case 3, attendees engaged in six short walks initiated by the demonstrator, each time to another point at the farm, ending at the new milking robots. Some of them touch a cow while passing by in the barn and everyone has to wear shoe covers when coming out of the presentation room 
and entering the new barn. Apart from these sensory experiences, smelling, watching and listening, participants are not engaged in other specific opportunities. Since a figure of the interactions with the environment over time during Case 3 would resemble the figure of Case 1, we did not include it.

In Case 1, we noticed a pattern we were not looking for. It seemed that when the demonstrator used verbal references to the immediate surroundings the group was standing in and looking at, this provoked questions by the participants, for example:

D (Demonstrator): "Now the cows are here (looks at field the group is looking out on). I work with a system that my cows move around different meadows. So sometimes the grass is long when the cows have not been there recently, and I leave the grass that long." P (Participant): "and after how many days/weeks do you move them?" D: "Normally 3 weeks." P: "How many cows do you have?" D: "I have 50 cows, as less (!) as possible. I do not know if you like to work very hard? Well I work very hard, but I want to work as less as possible to survive."

D: "I planted some oak and ash here (pointing at location close by). My environment of work is my landscape. So I make it beautiful for myself, I like the oak I like the ash, that's why." P: "How old are they?" D: "(Points at tree), that was the only one that was here when I came here. It was 'so' (shows thumb) thick in '94. These are 20 years old."

D: "I looked at the other side of the road and there were very big walnut trees, so I knew this would work...." (About ten minutes later) P: "You said that your neighbor also had walnuts?" D: "Yes, these walnuts are growing from a nut, my trees are grafted. The trees in the area are all trees that grew from seeds, nuts. And that is not the same. We can go and look if that's a good tree and take a graft from there, but there's no knowledge about that."

As in Case 2, when participants started discussing after physically examining the soil, observing and taking in the surroundings also seemed to provoke questions in Case 1. For example:

P: "Is this like your test area? Because I can see you have the room to try out?"

\subsection{Video Guidelines to Evaluate OFD as a Tactile Space}

Every participant will experience the OFD and tactile space opportunities in a slightly different way. One participant will engage easily and take initiative in conversations, discussions and sensory experiences, while others will not feel comfortable doing that without a slight nudge. Video can capture the authentic behaviour of participants and reactions to all sorts of invitations to take part in sharing knowledge or experience more-than-representational knowledge, in a rich supplementary way to participant observations, surveys and interviews.

The most important lesson for us here was that focussing simultaneously on both social interactions during the formal guided moments and trying to capture social interactions during informal moments was close to impossible. Two or more video cameras with one focusing on the formal moments and the other(s) on the more informal conversations and interactions would have been of benefit. Closely related to this is the importance of defining the analytical units clearly, so the researcher filming knows exactly what to focus on.

Inspired by the VDA methodological framework [18], our research and experiences as illustrated in the introduction, methodology and above result section led us to summarise our suggestions for applying this methodology to evaluate an OFD as a tactile space in Table 2. 
Table 2. Video guidelines to evaluate OFD as a tactile space.

\section{Before OFD:}

Use this methodology when your research agenda includes interest in:

- $\quad$ authentic behavior of people during an OFD;

- $\quad$ verbal and non-verbal interactions with both other attendees and the environment;

- $\quad$ tracing interactions during OFDs step-by-step to identify patterns that help explaining (learning) outcomes;

- $\quad$ finding out how participants learned through attending an OFD.

Decide clearly on analytical units and dimensions in terms of interactions and context elements:

- $\quad$ Physical embodiedness, for example through:

amount/frequency/duration of movements of attendees in the environment throughout the duration of the OFD;

amount/frequency/duration of use of items or other interactions with the surroundings;

Investigating the effect on participants of verbal references to the surroundings.

- $\quad$ Social embeddedness, for example through:

- amount/frequency/duration of a type (one-way explanation/questions/discussion/ ... ) of verbal communication during informal moments, compared to formal guided moments;

identifying how the demonstrator invites or engages participants towards interactions;

identifying how the presence of different roles (demonstrator, facilitator, group leader, etc.) shape the interactions during an OFD.

Criteria for validity:

- $\quad$ Ensure optimal capture of the OFD space and its participants through employing the right number of researchers. Each researcher could focus on another unit of analysis.

- Safeguarding the authentic behavior of participants by capturing qualitative audiovisual material as unobtrusively as possible, without violation of ethical requirements.

- $\quad$ Develop triangulation of data sources.

\section{During OFD:}

Explicit focus on units and dimensions of analysis:

- Use more than one researcher with a camera if units and dimensions of analysis will occur at the same time. Make sure every researcher knows their focus.

\section{After OFD:}

Analytical procedures:

- $\quad$ Coding audiovisual material multiple times, each time focusing on another unit of analysis. This leads to reconstruction of, for example, informal verbal, formal verbal and physical interactions for the duration of the OFD.

- $\quad$ Identifying patterns.

\section{Discussion}

It is not the first time that the concept of a tactile space has been used to reflect on learning during farm demonstrations. Apart from Carolan himself applying the concept to rural environments, Anglade et al. [25], for example, mentioned the concept as appropriate for grasping the dynamics of embedded and embodied knowledge sharing at an experimental farm station. They describe it as "an opportunity to mix distal and proximal forms of thinking ... to nurture new intelligibilities and behaviors towards agro-ecological systems thinking", and thus nurture deep commitments. They state that one central challenge was to "offer the conditions at the experimental farm station for dialogue inclusive of different types of knowledge within the perspective of sustainability". Their main suggestion in this regard is to foster sharing experiences between demonstrators and participants, 
allowing for strong reactivity to questions on what people are experiencing (observing, tasting, touching, hearing, etc.). This is in line with the main conclusion of our research, after analysing the audiovisual material of three OFDs. Having noticed a pattern of physical embodiedness opportunities shaping and stimulating verbal and physical interaction, and all three demonstrators using mainly one-way explanation, we conclude that a more elaborate and deliberate stimulation of physical experiences in all three cases could have been beneficial, both in terms of the amount of time and in variation. Debating sensory experiences (for example, verbally evaluating hands-on examination of the soil, but also deliberately using verbal references to surroundings as starting points for a dialogue) during formal moments could have created an even stronger learning and tactile space by inviting participants to engage in the dialogue and provoking questions, as we noticed in a glimpse during Case 1. Similarly, a more structural and deliberate inclusion of sensory experiences to be carried out by participants could be included during an OFD. Additionally, Case 3 showed us that the surroundings could also entail a barrier for verbal conversation with a big group of participants. This factor should not be neglected but considered beforehand. Leaving it up to the initiative of the participant to engage in sensory experiences, ask questions, start discussions, only using one-way verbal interaction or too silent verbal interaction might lead to not employing the full potential of an OFD as a learning space and ideal setting to stimulate the sharing of more-than-representational knowledge as well, creating tactile space. This implies that organisers and demonstrators have a crucial role in facilitating verbal as well as physical interactions. Future research could focus on identifying how the presence of different roles (demonstrator, facilitator, group leader, etc.) and how they are expressed shape different types of interactions and foster sharing of more-than-representational knowledge during an OFD.

In our opinion, the previously mentioned insights provided by this research indicate multiple other interesting paths for future research on the dynamics of physical embodiedness and social embeddedness fostering farmer learning during OFDs, which we could only reveal by examining the three OFDs as tactile spaces using audiovisual material. Of course, we fully acknowledge there are other influences on learning of a participant besides engaging in interactions during an OFD. To grasp other influences on farmer learning besides interactions during an OFD capture using video, triangulation with other data sources, such as interviews, focus groups or surveys, could be used in future research. These could provide us with information on the background (knowledge) of participants, their reasons for attending, or the impact of attending the OFD on the farming practices of individual participants to their own perception. In addition, interviews or focus groups could capture the impact of an OFD on the forming, strengthening, or weakening of related deep commitments. Therefore, specific questions could be asked during preferable interviews or focus groups, on, for example, the moments during the OFD they thought they learned the most from and why these moments specifically, or if and how they behaviour towards their environment changed and why. Surveys are also a possibility, but these are less controllable in terms of correct completion and interpretation of the questions by the participants. Another argument for triangulation is that personal sensory information, such as smell, something particular that caught their eye, or a feeling on the skin is not captured by audiovisual data. Questions in interviews could ask participants to describe the sensory experiences they had with the surroundings of an OFD and what they believe the impact of these experiences was on their learning. In retrospect, more audio excerpts of informal conversations between farmers could have provided us with additional valuable information to grasp discussion content and verbal reflection processes. An important difficulty and methodological challenge for future research aiming to incorporate this would be to capture informal conversations without disturbing the authentic behaviour of the participants with the presence of the researcher.

\section{Conclusions}

We learned lessons on two levels from studying the three videos of the OFDs through the lens of a tactile space. On the first level, we suggest there is room for improvement in organising and carrying out an OFD to reach its potential as a tactile space. For example, farmers gaining insight 
on the effect of a mechanical weeding machine on the soil through touching and smelling, in other words, sensory evaluating, is a good example of how an OFD can mediate more-than-representational knowledge. More experiences like this during an OFD could be beneficial for reflection and learning by the attending farmers. Our data suggests a pattern of physical embodiedness opportunities stimulating verbal and physical interactions, which could be a starting hypothesis for future research, together with evaluating the impact of different expressed roles on interactions during OFDs. Unraveling these dynamics in greater detail can provide us with further valuable insights into what role an OFD can play in learning in a socially embedded and physically embodied way about sustainable farming. Audiovisual material can capture these types of interactions in much more detail and allow for iterative data collection after the event by reviewing the footage, compared to data gathered through surveys or interviews. However, triangulation of data sources, combining, for example, audiovisual material of an OFD and longitudinal interviews, could provide more in-depth information on the impact of the social and physical interactions during the OFD on long-term farmer reflection, learning and deep commitment shaping.

This research resulted in multiple interesting insights and lessons learned for the future use of a methodology using video and other data sources to evaluate OFDs as tactile spaces, building on the VDA methodological framework of Nassauer and Legewie (2018). We summarised and presented these insights in Table 2, which could function as a starting point for methodological guidelines, adjustable for future research.

Author Contributions: Conceptualization, H.C., J.V., F.M.; Methodology, H.C., J.V., L.D. and F.M.; software, H.C.; validation, H.C., J.V., L.D. and F.M.; formal analysis, H.C.; investigation, H.C. and L.D.; resources, H.C., L.D. and F.M.; data curation, H.C., L.D. and F.M.; writing - original draft preparation, H.C.; writing-review and editing, J.V., L.D. and F.M.; visualization, H.C.; supervision, J.V., L.D. and F.M.; project administration, L.D. and F.M.; funding acquisition, L.D. and F.M. All authors have read and agreed to the published version of the manuscript.

Funding: This paper is funded by the European Union's Horizon 2020 research and innovation programme, under grant agreement No 728061 (AgriDemo-F2F).

Acknowledgments: This paper is linked to the AgriDemo-F2F project funded from the European Union's Horizon 2020 research and innovation programme under grant agreement No 728061.

Conflicts of Interest: The authors declare no conflict of interest. The funders had no role in the design of the study; in the collection, analyses, or interpretation of data; in the writing of the manuscript, or in the decision to publish the results.

\section{References}

1. Swanson, B.E. Global Review of Good Agricultural Extension and Advisory Practices. J. Agric. Educ. Ext. 2010, 16, 342-345. [CrossRef]

2. EU SCAR. Agricultural Knowledge and Innovation Systems in Transition-A Reflection Paper; European Commission: Brussels, Belgium, 2012. Available online: https://scar-europe.org/images/AKIS/Documents/ AKIS_reflection_paper.pdf (accessed on 24 April 2020).

3. Davis, K.; Nkonya, E.; Kato, E.; Mekonnen, D.A.; Odendo, M.; Miiro, R.; Nkuba, J. Impact of Farmer Field Schools on Agricultural Productivity and Poverty in East Africa. World Dev. 2012, 40, 402-413. [CrossRef]

4. Ingram, J.; Chiswell, H.M.; Mills, J.; Debruyne, L.; Cooreman, H.; Koutsouris, A.; Pappa, E.; Marchand, F. Enabling learning in demonstration farms: A literature review. Int. J. Agric. Ext. 2018, 29-42.

5. Prager, K.; Creaney, R. Achieving on-farm practice change through facilitated group learning: Evaluating the effectiveness of monitor farms and discussion groups. J. Rural Stud. 2017, 56, 1-11. [CrossRef]

6. Leeuwis, C.; Van den Ban, A. Communication for Rural Innovation: Rethinking Agricultural Extension, 3th ed.; Blackwell Science Ltd.: Oxford, UK, 2004.

7. Adamsone-Fiskovica, A.; Tisenkopfs, T.; Grivins, M. Formats, outcomes and impacts of knowledge exchange in demonstration activities. Xxvii Eur. Soc. Rural Sociol. Congr. 2017, 160-161.

8. Vanclay, F. Social principles for agricultural extension to assist in the promotion of natural resource management. Aust. J. Exp. Agric. 2004, 44, 213-222. [CrossRef] 
9. Franz, N.K.; Piercy, F.; Donaldson, J.; Westbrook, J.; Richard, R. Farmer, Agent, and Specialist Perspectives on Preferences for Learning Among Today's Farmers. Ext. Outreach Res. Scholarsh. 2010, 48, 3RIB1.

10. Cowan, J.S.; Goldberger, J.R.; Miles, C.A.; Inglis, D.A. Creating Tactile Space during a University Extension Field Day Event: The Case of a Sustainable Agriculture Innovation. Rural Sociol. 2015, 80, 456-482. [CrossRef]

11. Carolan, M.S. Introducing the concept of tactile space: Creating lasting social and environmental commitments. Geoforum 2007, 38, 1264-1275. [CrossRef]

12. Lorimer, H. Cultural geography: The busyness of being "more-than-representational". Prog. Hum. Geogr. 2005, 29, 83-94. [CrossRef]

13. Carolan, M.S. More-than-representational knowledge/s of the countryside: How we think as bodies. Sociol. Rural. 2008, 48, 408-422. [CrossRef]

14. Carolan, M.S. Ecological representation in deliberation: The contribution of tactile spaces. Environ. Politics 2006, 15, 345-361. [CrossRef]

15. Wals, A.; Dyball, R.; Brown, V.; Keen, M. Social Learning towards a Sustainable World: Principles, Perspectives, and Praxis, 2nd ed.; Wals, A., Ed.; Wageningen UR: Wageningen, The Nederlands, 2007.

16. Debruyne, L.; Cooreman, H.; Koutsouris, A.; Chiswell, H.; Ingram, J.; Mills, J.; Marchand, F. Methodological Guide for Data Gathering and Analysis: D3.1 Structural Characteristics D4.1 Functional Characteristics D5.2 Impact Assessment, 2017. AgriDemo-F2F H2020 728061. Available online: https://agridemo-h2020.eu/docs/D3.1-D4.1-D5.2\%20Methodological\%20guide\%20for\%20data\% 20gathering\%20and\%20analysis_v2.pdf (accessed on 24 April 2020).

17. Ramey, K.E.; Champion, D.N.; Dyer, E.B.; Keifert, D.T.; Krist, C.; Meyerhoff, P.; Villanosa, K.; Hilppö, J. Qualitative analysis of video data: Standards and heuristics. In Proceedings of the International Conference of the Learning Sciences (ICLS), National Institute of Education, Singapore, 20-24 June 2016; pp. 1033-1040.

18. Nassauer, A.; Legewie, N.M. Video Data Analysis: A Methodological Frame for a Novel Research Trend. Sociol. Methods Res. 2018. [CrossRef]

19. Vrij, A.; Hope, L.; Fisher, R.P. Eliciting Reliable Information in Investigative Interviews. Policy Insights Behav. Brain Sci. 2014, 1, 129-136. [CrossRef]

20. Derry, S.J.; Pea, R.D.; Barron, B.; Engle, R.A.; Erickson, F.; Goldman, R.; Hall, R.; Koschman, T.; Lemke, J.L.; Sherin, M.G.; et al. Conducting Video Research in the Learning Sciences: Guidance on Selection, Analysis, Technology, and Ethics. J. Learn. Sci. 2010, 19, 2-53. [CrossRef]

21. Rusk, F.; Pörn, M.; Sahlström, F.; Slotte-Lüttge, A. Perspectives on using video recordings in conversation analytical studies on learning in interaction. Int. J. Res. Method Educ. 2015, 38, 39-55. [CrossRef]

22. Jewitt, C. An introduction to using video for research An Introduction to Using Video for Research. In National Centre for Research Methods; Institute of Education: London, UK, 2012.

23. Hayden, J.; Buck, D. Doing Community Supported Agriculture: Tactile Space, Affect and Effects of Membership. GeoForum 2012, 43, 332-341. [CrossRef]

24. Derry, S.J. Guidelines for Video Research in Education: Recommendations from an Expert Panel; Data Research and Development Center: Chicago, IL, USA, 2007.

25. Anglade, J.; Godfroy, M.; Coquil, X. A device for sharing knowledge and experiences on experimental farm station to sustain the agroecological transition. In Proceedings of the 13th European IFSA Symposium, Chania, Greece, 1-5 July 2018.

(C) 2020 by the authors. Licensee MDPI, Basel, Switzerland. This article is an open access article distributed under the terms and conditions of the Creative Commons Attribution (CC BY) license (http://creativecommons.org/licenses/by/4.0/). 